\title{
Immunisations among school leavers: is there a place for measles-mumps-rubella vaccine?
}

H P Lashkari (drlhprasad@gmail.com) ${ }^{1}$, H El Bashir ${ }^{1}$

1. Child Development Centre, St Ann's Hospital, London, United Kingdom

Citation style for this article:

Citation style for this article: Lashkari HP, El Bashir H. Immunisations among school leavers: is there a place for measles-mumps-rubella vaccine? . Euro Surveill. 2010;15(17):pii=19555. Available online: http://www.eurosurveillance.org/ViewArticle.aspx?Articleld=19555

This article has been published on 29 April 2010

To ascertain measles-mumps-rubella (MMR) immunisation coverage among school leavers in an inner city London borough following a local MMR catch-up initiative, a questionnaire was sent to parents and guardians of adolescents who attended the 12 secondary schools in Haringey and were due for the school leavers' vaccination. The questionnaire enquired about previous history of MMR vaccination and a history of adverse events or contraindications to the vaccine. The electronic immunisation records of 400 children (30-35 students from each school) included in the catch up initiative were randomly selected. The childrens' school health records were manually compared with the electronic records. The mean age of the children was 14.7 years, and 224 (56\%) were male. Of the 373 records examined prior to the local MMR catch-up initiative, 98 children (26\%) had never received MMR, $173(46.5 \%)$ had only had one dose, 100 (27\%) had two doses, and two children had three doses of the vaccine. During the school leavers' MMR immunisation, 171 (43\%) received a dose of MMR and the number of children immunised with two doses increased to 206 (55.3\% versus $27 \%$ P $<0.001$ ), doubling the coverage. Offering MMR vaccination as part of the school leavers' immunisation is logistically convenient and it may limit the extent of outbreaks.

\section{Introduction}

In 1988 the measles-mumps-rubella (MMR) vaccine was introduced in the United Kingdom (UK) and offered to children aged 12-15 months (born after October 1987) [1]. A catch-up campaign for those who were born between 1983 and 1987 accompanied the launch. In 1994, a measles-rubella (MR) vaccine was offered to children born between January 1978 and March 1989 [1]. In October 1996 a second MMR dose was added at the same time as the preschool booster, with a catchup for those born between January 1990 and March 1992. For the first decade following its introduction in the UK, the MMR vaccine uptake was high, reaching $90 \%$ in most areas. With the adverse publicity (from 1998 onwards), the national uptake of the vaccine has fallen to $81 \%$ (in children up to the age of two years) and to less than $60 \%$ in some areas of London [2]. In 2005 , over 40,000 cases of mumps were reported to the Health Protection Agency; half of those cases were children in the age group from 15 to 19 years [3]. In 2006, 739 cases of measles were reported and 129 of those were between 10 and 19 years old [4].

Many studies have suggested that children and adolescents who had two doses of the MMR vaccine are better protected against measles, mumps and rubella compared with those who had only one dose of the vaccine [5-8]. Since 1990, the number of children born with congenital rubella has decreased and only 40 cases were reported for the period between 1991 and 2002 [9-11]. An uptake of $80 \%$ is required to prevent the circulation of rubella in the population. If the uptake is lower than that then the average age of infection rises, which leads to an increased risk for women of child bearing age [12].

In 2006, an increasing number of mumps cases were reported among secondary schools pupils in Haringey (North London). In an attempt to control the growing number of cases, we offered a catch-up dose of MMR to all adolescents who were leaving school in 2006 and had not previously had any or only one dose of the MMR vaccine.

\section{Methods}

A consent form which included a short questionnaire was sent to all parents and guardians of adolescents who attended the 12 secondary schools in Haringey and were due for the school leavers' vaccination, which includes diphtheria (low dose), tetanus, and inactivated polio vaccine (dT-IPV). The questionnaire enquired about previous history of MMR vaccination (number of doses and dates) and any history of adverse events or contraindications to the vaccine. If parents or guardians were unsure and there was no documentation of previous MMR vaccination in the child's school records, the vaccine was recommended. Those who consented to vaccination were given the MMR dose in school at the time of school leavers' vaccination. Immunisations in all secondary schools were conducted by school nurses. Immunisation records of those vaccinated were entered in the children services' electronic vaccination 
database that holds the vaccination records of children living in or attending a school in the borough.

Three months following the school MMR initiative, the electronic immunisation records of 400 students (30-35 from each school) born between 1 September 1990 and 31 August 1991 who were due for the school leaver's immunisation (dT-IPV) in 2006 were randomly selected. We then examined the records to ascertain firstly, the number of MMR doses given previously and secondly, if the student received a dose of MMR following the school leavers' vaccination initiative. Because of concerns over the completeness of electronic immunisation records, we also reviewed the childrens' school health records for ascertainment and validation of the MMR vaccine history.

\section{Results}

The mean age of children was 14.7 years and 224 (56\%) were males. Based on information gathered from the school health and electronic immunisation records prior to the catch-up activity, 27 of 400 (8\%) immunisation records were either missing or incomplete. Of the remaining 373 records, 98 (26\%) had never received MMR vaccine, 173 (47\%) had had one dose, 100 (27\%) had had two doses, and two children had received three doses of the vaccine. During the school leavers' MMR vaccination a total of $173(47 \%)$ children received a dose of MMR vaccine increasing the number of those who had a total of two doses to 206 (55.3\% versus $27 \%$ P<0.001) (Table). The reasons for MMR vaccine refusal were not mentioned in the medical records.

\section{Discussion}

To our knowledge, no previous studies have looked at the feasibility and benefits of giving MMR immunisation as part of the school leavers' vaccination (as a catch-up initiative) for those who had received no or only one dose of MMR vaccine previously. The children in the study were born between 1990 and 1991 and hence a significant proportion had only one dose of MMR vaccine as they may have missed the second dose introduced in 1996. As one dose of the vaccine offers only $80-85 \%$ efficacy against mumps [13], a large number of children in this study are at risk of acquiring this disease. Moreover, part of the same group of children are also not fully protected against measles because of their incomplete vaccination [6]. This was clear from recent measles outbreaks where almost one in five cases were adults [14].

Following the school immunisation, the risk of these infections was reduced by more than twofold. However, the number of children who had two doses of MMR and could therefore be considered to have adequate protection against measles, mumps and rubella is still very low (55\%). The low MMR uptake may explain the outbreaks of mumps among older school children and university students. This group might also have contributed indirectly, because of low herd immunity, to the increasing number of measles cases in younger age groups. Rubella has been eliminated from the United States (US) and Scandinavian countries except for occasional imported infections. In the UK, there is a danger of rubella infection in unvaccinated young women in the future due to earlier low uptake of MMR vaccine [11]. As some parents may be particularly reluctant to immunise very young children with MMR, they may be more willing to do so when the children are older and therefore more likely to accept such catchup campaigns. Providing this vaccine in school and at the same time as the school leavers' immunisation is logistically convenient and it may limit the extent of mumps and measles outbreaks which may involve also younger children who are not fully vaccinated.

Some evidence of waning immunity was found, with the estimated vaccine effectiveness declining from $99 \%$ in $5-6$ year old children to $86 \%$ in $11-12$ year-olds during the large outbreak in the UK in 2004-2005 [15]. Waning immunity has been postulated as one of the contributing factors for the large mumps outbreak in 2005 in Canada because young adults in the age group of 18-24 year-olds would most commonly have received their most recent dose of mumps-containing vaccine six to 17 years previously $[16,17]$. Despite high coverage with two doses of mumps vaccine large outbreaks of mumps have been happened in the US [18]. If population immunity is already near the herd threshold, even negligible waning immunity, particularly when combined with increased exposure, could potentiate an outbreak [19].

\section{TABLE}

Coverage with measles-mumps-rubella vaccine among school leavers before and after catch-up immunisation at schools, North London, $2006(\mathrm{n}=400)$

\begin{tabular}{|l|c|c|c|}
\hline Number of MMR doses & $\begin{array}{c}\text { Before school leavers' MMR vaccination } \\
\text { Number (percentage } \mathbf{9 5} \mathbf{9} \mathbf{~ C l})\end{array}$ & $\begin{array}{c}\text { After school leavers' MMR vaccination } \\
\text { Number (percentage } \pm \mathbf{9 5} \% \mathbf{~ C l )}\end{array}$ & Change in number of vaccine doses \\
\hline 0 & $98(26 \pm 4 \%)$ & $33(9 \pm 3 \%)$ & $-66 \%$ \\
\hline 1 & $173(47 \pm 5 \%)$ & $132(36 \pm 5 \%)$ & $-24 \%$ \\
\hline 2 & $100(27 \pm 4 \%)$ & $206(55 \pm 5 \%)$ & $106 \%$ \\
\hline Unknown & 27 & 27 & \\
\hline$>2$ doses & $2(0.5 \%)$ & $2(0.5 \%)$ & \\
\hline
\end{tabular}

$\mathrm{Cl}$ : confidence interval; MMR: measles-mumps-rubella vaccine. 
MMR vaccination for the school leavers will help to boost the herd immunity, but further studies are needed to establish the potential for waning of immunity in adolescents and young adults. Notwithstanding, every effort should be made to improve the MMR uptake in younger children who are at greater risk of the three diseases.

\section{References}

1. Salisbury D, Ramsay M, Noakes K, editors. Immunisation against infectious disease, 2006; 3 rd ed. Department of Health, London: chapter 21, 23, 28.

2. Department of Health. Health and social care information centre, NHS Immunisation Statistics, England: 2004-2005. Available from: http://www.dh.gov.uk/ assetRoot/04/11/96/50/04119650.pdf

3. Health Protection Agency. Mumps Notifications, by Age group, 1989-2007. [Internet]. Available from: http://www.hpa.org.uk/ webw/HPAweb\&HPAwebStandard/HPAweb_C/1195733844620 $? p=1191942172913$

4. Health Protection Agency. Confirmed cases of measles by region and age: 1996 -2007. [Internet]. Available from: http://www.hpa.org.uk/web/HPAweb\&HPAwebStandard/ HPAweb_C/1195733778332

5. Paunio M, Peltola H, Valle M, Davidkin I, Virtanen $M$ Heinonen OP. Twice vaccinated recipients are better protected against epidemic measles than are single dose recipients of measles containing vaccine: J Epidemiol Community Health. 1999;53(3):173-8.

6. Morse D, O'Shea M, Hamilton G, Soltanpoor N, Leece G, Miller $E$, et al. Outbreak of measles in a teenage school population: the need to immunize susceptible adolescents, Epidemiol Infect. 1994:113(2):355-65.

7. Plotkin SA, Orenstein WA. Vaccines, 2004, 4th ed, Philadelphia, WB Saunders Company: Chapter 19-20.

8. Harling R, White JM, Ramsay ME, et al. The effectiveness of the mumps component of the MMR vaccine: a case control study. Vaccine. 2005;23(31):4070-4

9. Health Protection Agency (HPA). Confirmed cases of Measles, Mumps and Rubella 1996-2008. Available from: http://www.hpa.org.uk/web/HPAweb\&HPAwebStandard/ HPAweb_C/1195733833790

10. Health Protection Agency (HPA). Vaccination coverage statistics for children up to five years of age in the United Kingdom. Immunisation. Commun Dis Rep CDR Wkly 2004;14(4). [Internet]. Available from: http://www.hpa.org.uk/ cdr/pages/immunisation.htm\#COVER_jul_sep

11. Tookey P. Rubella in Scotland, Wales and England. Euro Surveill. 2004;9(4). pii=464. Available from: http://www. eurosurveillance.org/ViewArticle.aspx?Articleld=464

12. Hinman AR, Irons B, Lewis M, Kandola K. Economic analyses of rubella and rubella vaccines: a global review. Bull World Health Organ. 2002; 80(4):264-70.

13. Miller E, Hill A, Morgan-Capner P, Forsey T, Rush M. Antibodies to measles, mumps and rubella in UK children 4 years after vaccination with different MMR vaccines. Vaccine. 1995;13(9):799-802.

14. Eaton L. Measles cases in England and Wales rise sharply in 2008 BMJ. 2009;338:b533, doi: 10.1136/bmj.b533.

15. Cohen C, White JM, Savage EJ, Glynn JR, Choi Y, Andrews N. Vaccine effectiveness estimates, 2004-2005 mumps outbreak, England. Emerg Infect Dis. 2007:13(1):12-7.

16. Conly JM, Johnston B. Is mumps making a comeback? Can J infect Dis Med Microbiol. 2007;18(1):7-9.

17. Watson-Creed G, Saunders A, Scott J, Lowe L, Pettipas J, Hatchette TF. Two successive outbreaks of mumps in Nova Scotia among vaccinated adolescents and young adults. CMAJ. 2006;175(5):483-8.

18. Dayan GH, Quinlisk MP, Parker AA, Barskey AE, Harris ML, Schwartz JM, et al. Recent resurgence of mumps in the United States. N Engl J Med. 2008;358(15):1580-9.

19. Date AA, Kyaw MH, Rue AM, Klahn J, Obrecht L, Krohn T, et al. Long-term persistence of mumps antibody after receipt of 2 measles-mumps-rubella (MMR) vaccinations and antibody response after a third $M M R$ vaccination among a university population. J Infect Dis. 2008;197(12):1662-8 